\title{
Young children and adults associate social power with indifference to others' needs
}

\author{
Brandon F. Terrizzi ${ }^{1}$ \\ Amanda M. Woodward ${ }^{2}$ \\ Jonathan S. Beier ${ }^{2}$ \\ ${ }^{1}$ Cincinnati Children's Hospital Medical Center, Cincinnati, Ohio, USA \\ ${ }^{2}$ University of Maryland, College Park, Maryland, USA
}

This paper is in press at the Journal of Experimental Child Psychology. This preprint may differ from the final copy-edited version.

Disclosures \& Funding: The authors declare that they have no conflicts of interest. This research did not receive any specific grant from funding agencies in the public, commercial, or not-for-profit sectors.

The original materials and data accompanying this study are available at the Open Science Framework: https://osf.io/36yz2/?view only=5ac38a83c8814841a92daf9bc9a4bb82.

\section{Word counts:}

Manuscript: 8761 words (includes references)

Abstract: 238/250 words

\section{Corresponding Author Information:}

Brandon F. Terrizzi, PhD

Division of General \& Community Pediatrics

Cincinnati Children's Hospital Medical Center

3333 Burnet Avenue

Cincinnati, OH 45229

Email: Brandon.Terrizzi@cchmc.org

Phone: +1 5138038817 
RUNNING HEAD: POWER AND PROSOCIAL RESPONSIVENESS

\section{Highlights}

- From 4 years, children view an unhelpful person as an authority figure.

- From 6 years, they predict subordinates, not authorities, will help third parties.

- But they do not view helping or being helped as diagnostic about authority.

- Once children hold consistent views, these match adults' intuitions.

- Overall, people more easily associate authority with indifference to others' needs. 


\begin{abstract}
In hierarchical societies, what do we expect from people at the top? Early in life, children use horizontal relationships (e.g., affiliation) to predict selectivity in others' prosocial behavior. But it is unknown whether they also view asymmetries in prosocial behavior as characteristic of vertical relationships (e.g., differences in social power). In two experiments, we investigated 4to 7-year-old children's and adults' $(\mathrm{N}=192)$ intuitions about links between relative authority status, helpful action, and unhelpful inaction. In Experiment 1, participants at all ages viewed a character who chose not to help another person as holding a position of authority over them; they also viewed this unhelpful character as less nice than the person in need. However, no age group made consistent inferences about the relative authority of a helper and helpee. In Experiment 2, children had mixed intuitions when separately predicting whether high- and low-authority characters would be helpful in the future. However, older children and adults consistently indicated that a subordinate would be more likely than an authority to help a third party. These findings establish that children's social theories include expectations for links between power and prosociality by at least the preschool years. Whereas some judgments in this domain are stable from 4 years onward, others emerge gradually. Whether consistent responses occurred early or only later in development, however, all measures converged on a single intuition: People more easily associate authority with indifference to others' needs.
\end{abstract}

Keywords: social dominance, social status, prosocial behavior, helping, social evaluation, social-cognitive development 
RUNNING HEAD: POWER AND PROSOCIAL RESPONSIVENESS

Hierarchical societies distribute social power unevenly across their populations. Whereas some people hold positions of wealth and authority, others have lower status, fewer resources, and less influence over others. As children become familiar with the hierarchical structure of their own social environments, what more do they expect from people at the top? In children's views, will powerful people look out for the less fortunate, or does high rank bring indifference to others' needs?

From early in life, children have intuitions about the role of power within dyadic social interactions. Even infants can identify the more physically dominant of two individuals (Mascaro \& Csibra, 2012; Pun, Birch, \& Baron, 2016; Thomsen, Frankenhuis, Ingold-Smith, \& Carey, 2011), and toddlers distinguish between leaders and bullies (Margoni, Baillargeon, \& Surian, 2018; Thomas, Thomsen, Lukowski, Abramyan, \& Sarnecka, 2018) . By the time children reach preschool age, they understand that power differentials affect a wide range of interpersonal behaviors (Brey \& Shutts, 2015; Charafeddine et al., 2014; Enright, Gweon, \& Sommerville, 2017; Gülgöz \& Gelman, 2016; Terrizzi, Brey, Shutts, \& Beier, 2019; Thomas et al., 2018), expecting authority figures to win zero-sum contests and to establish how others should behave (Charafeddine et al., 2014; Gülgöz \& Gelman, 2016).

Young children are also aware that social relationships capture important regularities in people's prosocial behaviors toward one another. Research in this area has focused on preschoolers' recognition that affiliative relationships - notably, friendship, kinship, and shared group membership — are partially constituted by the provision of prosocial support (Jin \& Baillargeon, 2017; Liberman \& Shaw, 2017; Spokes \& Spelke, 2016). Yet no research has investigated children's intuitions about links between power and prosocial behavior. Because naturally forming social groups have both affiliative and hierarchical structure (Cheng, Tracy, \& 
RUNNING HEAD: POWER AND PROSOCIAL RESPONSIVENESS

Henrich, 2010; Henrich \& Gil-White, 2001), more research is necessary to build a complete account of children's intuitions regarding the conditions under which people can expect help.

The real-world associations between power and prosociality are complex. Research with adults suggests two broad patterns (Barclay, 2013; Guinote, 2017; Kafashan, Sparks, Griskevicius, \& Barclay, 2014). Greater power is sometimes associated with greater prosociality. This may arise from strategic motivations to secure one's privileged status (Kafashan et al., 2014; van de Ven, Zeelenberg, \& Pieters, 2010) or from internalized social norms encouraging the powerful to act beneficently toward those with less power-a principle known as noblesse oblige. Merely adopting the perspective of a high-ranking authority leads adults to exhibit prosocial dispositions, such as tolerating free-riding by lower-ranked people (Fiddick, Cummins, Janicki, Lee, \& Erlich, 2013), feeling greater social responsibility (Côté et al., 2011; Scholl et al., 2018), and experiencing an enhanced moral identity (DeCelles, DeRue, Margolis, \& Ceranic, 2012).

However, power is also associated with less prosocial—and even antisocial—behavior. Feeling powerful may engender the desire to prevail over others (Guinote, 2017) and a release from social conventions (Van Kleef, Homan, Finkenauer, Blaker, \& Heerdink, 2012). Inducing adults' subjective feelings of power (e.g., by asking them to recall past experiences of control or to reflect on their privileged status) reduces support for others' goals, perspective-taking, and empathic accuracy (Galinsky, Magee, Inesi, \& Gruenfeld, 2006; Kraus, Côté, \& Keltner, 2010; Laurin et al., 2016), and participants assigned to high status groups adopt predatory bargaining strategies (Ball, 1998).

These complex patterns are also reflected in young children's sociality, where power is linked with both prosocial and antisocial behavior. In preschool groups, the most popular and 
RUNNING HEAD: POWER AND PROSOCIAL RESPONSIVENESS

socially dominant children exhibit a combination of prosocial and coercive strategies to control resources and obtain social favor (Grueneisen \& Tomasello, 2017; Hawley, 2002). However, less popular children (Horn, Hungerländer, Windhager, Bugnyar, \& Massen, 2018), and children who experience an experimentally induced loss of resources (Guinote, Cotzia, Sandhu, \& Siwa, 2015), make relatively more prosocial distribution choices than high status peers. Additionally, children assigned to a "losing" versus a "winning" group exhibit greater perspective-taking abilities (Pellegrini et al., 2011; Rizzo \& Killen, 2018).

All this complexity adds up to a challenging learning environment. As children construct theories about their social world, it is unclear what intuitions they form about the links between power and prosociality, and how these intuitions develop with increasing social experience. To the extent that children encounter some of these real-world regularities in their own experiences and observations, it is possible that they build detailed knowledge of them. Alternatively, the complexity may be too much. Young children may not yet recognize the regularities within their wide-ranging experiences, or they may not be able to resolve their complexity by drawing sufficient distinctions between different social contexts, forms of power, and varieties of prosocial behavior; in either case, they may not hold any expectations about power and prosociality at all.

\section{The Current Studies}

As a first step toward understanding developments in children's intuitions about power and prosociality, we investigated 4- to 7-year-olds' and adults' expectations for links between relative authority, helpful action, and unhelpful inaction. Experiment 1 examined whether participants infer which of two people is "in charge" after witnessing one of them choose to help or not help the other. Experiment 2 examined whether participants use one person's authority 
RUNNING HEAD: POWER AND PROSOCIAL RESPONSIVENESS

status to predict their prosocial responsiveness to another person. By assessing participants' judgments in both directions, and about both helping and not helping, this overall design addresses our primary research question: Do children hold any intuitions about links between power and prosocial responsiveness at all?

As reviewed above, the real-world associations between power and prosociality support competing directional predictions. If participants associate authority with helpful responding, they should identify helpful characters as having power over those whom they help, predict that people high in power will be helpful, or both. However, if they view authority figures as more likely to be indifferent to others' needs, they should identify characters who unhelpfully do nothing as having power over those who require help in their presence, predict that people high in power are unlikely to be helpful, or both. We anticipated that patterns of responses across measures might provide insight into the types of experiences and observations that contribute most to children's developing intuitions.

We focused on intuitions about authority for several reasons. Unlike other sources of power (e.g., physical formidability), normative authority does not require other physical attributes that would also support an increased ability to help others. Based on prior work (e.g., Terrizzi et al. 2019), we adopted a more general description of authority (i.e., “...getting to make all the rules and tell others what to do") instead of asking participants to reason about specific examples, such as a parent or teacher. Our intention was to encourage reasoning about a basiclevel concept of authority, rather than particular authority types or specific exemplars of these subordinate categories. An additional motivation is that authority is defined by norms about what one can or should do: Authority rests on social consensus and so is partly subject to a person's adherence to others' expectations, but it also grants some provenance over what norms are 
relevant in a given context. Although it is an open question whether children understand these aspects of authority, focusing on authority thus highlights considerations likely central to adults' intuitions about normative prosociality, and our cross-sectional design can inform whether children's judgments match the judgments made by adults.

Of the many varieties of prosocial support, we focused on participants' reasoning about the provision of low-cost instrumental help. Helping in these situations is straightforward and easily understood by preschoolers. As noted above, it also does not require exceptional strength (Terrizzi et al., 2019) or material resources (Charafeddine et al., 2014), which may themselves be indications of power.

Several considerations guided our selection of ages. By 4 years, children are already knowledgeable about social power and have provided consistent, sensible responses using the same authority definition employed here (Gülgöz \& Gelman, 2016; Terrizzi et al., 2019).

Because expectations for affiliation-based selective prosociality continue to develop through age 7 (e.g., Liberman \& Shaw, 2017), we reasoned that children's intuitions about power and prosociality might as well. Further, although substantial research had documented associations between adults' status and their prosocial responsiveness, no studies to our knowledge have examined adults' generalized intuitions about this link. We thus assessed adults' intuitions for two reasons: to establish a "mature" outcome for contrast with children's responses that would reveal whether further experiences past age 7 may impact children's thinking, and to provide a novel contribution to the literature on adults' conceptions of social life.

\section{Experiment 1}


RUNNING HEAD: POWER AND PROSOCIAL RESPONSIVENESS

In Experiment 1, participants viewed live-action videos in which one person required instrumental help and another person either did or did not help her. After presenting each video, we asked participants to indicate which of these two people was "in charge".

We also assessed participants' judgments about the relative niceness of the same characters. Prior research shows that non-helpers are generally viewed as not nice (BLINDED, in prep), but it is unknown whether preschoolers view authority figures as beholden to the same prescriptive prosocial norms as others. If participants label unhelpful characters as authorities, this might influence their subsequent niceness judgments, such that they no longer view these unhelpful characters as less nice. Because this reasoning rests on multiple assumptions (i.e., that participants associate unhelpfulness and authority; that labeling an authority prompts revision of an initial impression of not-niceness), however, we treated the "niceness" question as an initial, exploratory inquiry that could motivate future research in this area. We also anticipated a more limited use of this measure: If participants' responses did not reveal associations between power and prosociality, niceness ratings could provide additional confirmation that they understood the video events and were comfortable providing answers to a question for which they might have a clearer intuition.

\section{Method}

Participants. Sixty-four 4- to 7-year-old children, divided equally across two age groups (younger children: 4- to 5-year-olds, $M_{\text {age }}=4.92$ years, $S D=.57$ years, 17 female; older children: 6- to 7-year-olds, $M_{\text {age }}=6.98$ years, $S D=.59$ years, 19 female), and 32 adults $\left(M_{\text {age }}=\right.$ 20.91 years, $S D=2.45$ years, 24 female) participated. An a priori power analysis for the binomial analyses conducted in each age group indicates that the sample size required to detect a 
RUNNING HEAD: POWER AND PROSOCIAL RESPONSIVENESS

"medium" effect (proportion selecting one character $=.75$, power $=.80$ ) is 29 participants, confirming that this study had sufficient power.

Children were typically developing, exposed predominately to English (all daily inputs $\geq 70 \%$ ), and majority White and Non-Hispanic (55\%); see Table S1 for a more complete breakdown of children's parent-reported race and ethnicity. The modal parent-reported annual family income exceeded $\$ 100,000$. Children participated at a children's museum in [location], without compensation. Adults were [University] students receiving course credit.

Thirteen additional children were excluded because they did not complete the study (3 younger children), did not understand the provided definition of being "in charge" (3 younger children), failed the method check ( 3 younger children, 2 older children), or did not meet the language requirement ( 2 older children).

Twelve additional adults were excluded because they did not complete the study (5), were likely distracted (6; recorded study duration $>15 \mathrm{~min}$; mean was $4.60 \mathrm{~min}, S D=3.56$ ), or recognized a video actor as a familiar co-student (1).

Materials. Children viewed the study on an INSIGNIA-brand tablet computer (10-inch display, 1280-by-800 pixel resolution). Adults completed the study online.

On each of two trials participants watched a video featuring two female actors (approximately 30 seconds). These videos were used in a prior investigation of children's evaluations of others' prosocial responsiveness (BLINDED, in prep) and are available at (https://osf.io/36yz2/?view_only=5ac38a83c8814841a92daf9bc9a4bb82).

In both videos, two women enter a scene without speaking. One woman sits down to read. The other begins hanging a poster. Realizing she left her adhesive tape nearby, this woman holds the poster against the wall with one hand while reaching for the tape with the other. It is 
clear she cannot obtain the tape without help. The reading woman looks up and observes the situation, makes brief eye-contact with the woman in need, and alternates her attention between the other woman's reaching and the tape on the table. At this point, the videos diverge between conditions. In the Helpful Condition, the reading woman stands up, grabs the tape, places it in the reaching woman's hand, and sits down to continue reading. In the Unhelpful Condition, the reading woman returns to her book without helping. Both videos end with both characters in similar physical positions. The reaching woman never makes a verbal request for help.

Given the parallels between videos, we refer to the helpful and unhelpful actors as the "focal" characters of each condition. We used four actors total, in fixed pairs; within each pair one actor was always the focal character. To aid recognition and discrimination between actors, the focal actors wore distinctively colored shirts and were introduced by name. To control for side preferences, we created horizontally mirrored versions of all stimuli.

Procedure. See Figure 1. The experimenter began by displaying one actor pair and introducing the characters from left to right, e.g. "This is [character's name]. She's wearing [color of shirt]." Next, the experimenter advanced to a blank screen and explained that they would watch a video of these two girls. The experimenter encouraged the child to think about which girl is "in charge" and provided an age-appropriate definition: "A person who is in charge gets to make all the rules and gets to tell others what to do".

After the video, the screen auto-advanced to the same image used during the introduction. The experimenter asked two questions in fixed order, "Which of these girls is in charge?" and "Which of these girls is nicer?" The experimenter never provided feedback or further comments on the video or characters. Following these test questions, the experimenter repeated the above steps for the second actor pair and video. 
RUNNING HEAD: POWER AND PROSOCIAL RESPONSIVENESS

The study concluded with a method check confirming that children recalled the characters' behaviors. The experimenter displayed an image of the focal character from each video and asked, "Earlier, one of these girls was helpful and handed something to someone when they needed it. Can you point to the girl who was helpful?"

Adults completed an identical sequence, with written task instructions.

Design. Participants completed 2 trials and answered 2 questions per trial, comprising a within-subject 2 (Condition: Helpful, Unhelpful) x 2 (Question Type: "In Charge", "Nicer") design. Across participants, we counterbalanced condition order, which actor pair featured in each condition, and the left-right mirroring of the videos. During the introduction and test questions, the left-right position of the focal and needy characters matched the corresponding video. During the method check, the left-right positioning of the helpful and unhelpful characters was linked to the order of conditions.

Coding. For each question, children responded by pointing to one of the characters. Responses were coded for selecting either the focal character (i.e., the helpful or unhelpful character) or the character needing help, and for correctly answering the method check.

Two independent coders recorded the responses of 55 children (approx. 86\%) from video recordings of their participation $(\kappa=.96)$; disagreements were resolved by discussion. The caregivers of 9 children consented to only a written record of the child's responses.

Statistical Approach. Preliminary analyses found no influence of any of the counterbalancing factors or participant gender. Most importantly, the order in which participants encountered each condition did not significantly influence their responses.

The main analyses proceeded in two steps, conducted separately for each question. First, we created a Generalized Linear Mixed Model, utilizing a binomial link function, fit by 
RUNNING HEAD: POWER AND PROSOCIAL RESPONSIVENESS

maximum likelihood with Laplace approximation and a random intercept term identifying subjects to account for repeated measures. Condition, Age Group, and their interaction were included as predictors of participants' dichotomous judgments across trials. Each main effect was assessed using a Type-II Wald chi-square test when the interaction term was not significant, and a Type-III test otherwise. Second, we conducted binomial tests for each combination of Age Group and Condition (chance $=.50)$. The Supplementary Materials presents additional analyses, including phi tests of association between responses to each question type (Table S2).

\section{Results}

Figure 2 presents the proportion of trials in which participants selected the focal character.

Who's in charge? There was a main effect of Condition, $\chi^{2}(1)=16.66, p<.001$, but no effect of Age Group, $\chi^{2}(2)=3.78, p=.151$, nor an interaction between these factors, $\chi^{2}(2)=.96$, $p=.619$. In the Helpful condition, participants did not have consistent intuitions about the relative authority of the characters at any age (younger children: 15/32 chose the helper, $p=$ .860 ; older children: $11 / 32, p=.110$; adults: $17 / 32, p=.860)$. In the Unhelpful condition, all groups viewed the unhelpful character as holding authority over a character in need (younger children: 23/32, $p=.020$; older children: $23 / 32, p=.020$; adults: $28 / 32, p<.001$ ).

Who's nicer? There was a main effect of Condition, $\chi^{2}(1)=5.07, p=.024$, no effect of Age Group, $\chi^{2}(2)=5.97, p=.051$, and a significant interaction between these factors, $\chi^{2}(2)=$ $7.39, p=.025$. The effect of Condition was largest for older children (McNemar test; younger children: $\chi^{2}(1)=8.07, p=.005$; older children: $\chi^{2}(1)=28.00, p<.001$; adults: $\chi^{2}(1)=18.00, p$ $<.001)$. In the Helpful Condition, only older children viewed the helpful character as nicer than the character in need $(30 / 32, p<.001)$; neither younger children nor adults shared these 
RUNNING HEAD: POWER AND PROSOCIAL RESPONSIVENESS

intuitions (younger children: 19/32, $p=.377$; adults: $21 / 32, p=.110$ ). In the Unhelpful condition, all groups viewed the character in need as nicer than the unhelpful character (younger children: 24/32, $p=.007$; older children: 30/32, $p<.001$; adults: 29/32, $p<.001$ ).

\section{Discussion}

This experiment answers our primary research question. Both 4- to 7-year-old children and adults hold at least one intuition linking power and prosociality: When determining who is in charge, they associate unresponsiveness to another's need with greater authority status. In contrast, we did not obtain evidence for intuitions linking being helpful with having more or less authority.

What might explain participants' inferences about power from unhelpful inaction, but not from helpful action? One possibility is that they assume a world in which authorities and subordinates typically help one another, but where authorities are also more likely to withhold help. To illustrate, consider a hypothetical scenario in which authorities help subordinates $80 \%$ of the time and subordinates help authorities $90 \%$ of the time. Observing one person help another provides poor evidence regarding their relative power, because both authorities and subordinates help at high rates - however, a person who chooses not to help someone in need is twice as likely to hold authority over them than the reverse.

To be clear, the intuitive model described above is just one example of how participants' expectations about power and prosociality might give rise to the patterns observed in Experiment 1 - other models are possible. One way to investigate these issues is to ask whether people expect authorities and subordinates to help one another at similar rates. Experiment 2 takes this approach, by presenting participants with videos depicting the same instrumental needs shown in 
Experiment 1 and assessing whether a potential helper's authority status influences their predictions that she will help.

A secondary result from Experiment 1 is that participants across all ages negatively evaluated a person who did not help another person in need. This provides some insight into our exploratory question about the prosocial obligations of authority figures: Although participants did label unhelpful characters as being in charge, they also indicated that they were less nice than those who required help. This was consistent with prior work, in which young children have described unfamiliar, unhelpful people as not nice (BLINDED, in prep). An alternative outcome, in which first making authority judgments reduced this negative evaluation, would have provided preliminary evidence that recognizing a person's authority status mitigates the wrongness of their unhelpfulness. However, the present findings do not support this conclusion.

\section{Experiment 2}

Experiment 2 assessed the influence of a person's authority status on participants' predictions for whether or not they will be helpful. We did this in two ways. First, we asked participants to separately predict whether people who hold either higher or lower authority would help another person. Second, we asked the same participants to indicate whether a person in need would be more likely to be helped by an authority or subordinate.

Although these two measures are highly related, using them together provides a clearer picture of participants' intuitions. Because the first measure assesses participants' separate predictions for what an authority and a subordinate will do, it reveals their specific expectations about the likely prosocial responsiveness of people in each role; moreover, if participants make different predictions across roles, this would indicate that information about a person's authority status influences expectations about their prosocial responsiveness. However, we also anticipated 
RUNNING HEAD: POWER AND PROSOCIAL RESPONSIVENESS

that participants may view both authorities and subordinates as each likely (or unlikely) to help. In this case, the second, forced-choice measure is a better assessment of participants' intuitions about the relative prosocial responsiveness of authorities and subordinates.

\section{Method}

Participants. Sixty-four 4- to 7-year-old children, divided equally across two age groups (younger children: 4 - to 5-year-olds, $M_{\text {age }}=5.15$ years, $S D=.54$ years, 20 females; older children: 6- to 7-year-olds, $M_{\text {age }}=6.98$ years, $S D=.59$ years, 15 females) and 32 adults $\left(M_{\text {age }}=\right.$ 20.19 years, $S D=6.36^{1}$ years, 21 females) participated. The sample size was chosen to match Experiment 1.

As in Experiment 1, children were typically developing and exposed predominately to English. To facilitate rapid on-site testing we did not collect additional demographic information, but children in Experiment 2 participated either at the same museum as in Experiment 1 or an on-campus laboratory at [location] that draws families with a similar profile. Adults were [University] students receiving course credit.

Ten additional children were excluded because they did not complete the study (1 younger and 1 older child), did not meet the language requirement (1 younger and 3 older children), because of parent-reported developmental delay ( 2 younger children and 1 older child), or because of experimenter error (1 younger child). All children included in the final analyses passed the Trial 3 method check.

Eleven additional adults were excluded because they did not complete the study (2), recognized a video actor as a familiar co-student (5), or because their inclusion exceeded our

\footnotetext{
${ }^{1}$ This high SD was the result of a single older (55 years) participant.
} 
RUNNING HEAD: POWER AND PROSOCIAL RESPONSIVENESS

prespecified sample size of 32 participants (4). These latter participants were simply the last 4 of the 36 participants who completed the study and did not recognize any of the actors.

Materials. Children viewed the study on a 15-inch 2015 MacBook Pro computer (1280by-1800 pixel resolution) at a distance of approximately 45 inches. Adults completed the study online.

On the first two trials, participants viewed slightly modified versions of the videos from Experiment 1, including the same actor pairs and preliminary events. However, these videos ended during the Display of Need phase (i.e., when the reading woman observes the other woman reaching for the tape; see Figure 1), with the final frame of the edited videos remaining visible on screen. At no point did the video or the final frame provide any indication about how the reading woman would respond to the character in need. To maintain continuity with Experiment 1, we continue to refer to the reading woman in each video as the "focal" character.

On the third and final trial, participants were introduced to a new group of characters. After this introduction, they saw a video in which one of the characters walks into a room alone while carrying an armful of boxes. She subsequently drops one of the boxes over a small fence and then struggles to reach for it while keeping ahold of the other boxes. This video ends during her fully outstretched reach for the box, with the final frame remaining visible on screen. Because Experiment 2 involved more characters than Experiment 1, to reduce memory load the images used to introduce each character remained visible below the Display of Need video while it played.

Procedure. See Figure 3. The experimenter began by defining the term "in charge" using the same definition used in Experiment 1. 
RUNNING HEAD: POWER AND PROSOCIAL RESPONSIVENESS

Trials 1 and 2: "Will she help?" The experimenter advanced to an image displaying one actor pair and introduced each character as in Experiment 1. After this introduction, the experimenter indicated which of the two characters was "in charge" of the other and then played the video featuring them. When the video concluded, the experimenter summarized the situation and reminded the child which character was in charge: "The video stopped, but it looks like [character's name] needs help. She can't reach the tape on the table. Remember [appropriate character's name] is in charge, she gets to make all the rules. [She/other character's name] is reading right now." Then the experimenter asked the child to make a prediction: "Do you think that [character's name] will stop to help [character's name] or keep reading?" The experimenter repeated this procedure for the second trial, featuring the other actor pair.

Trial 3: "Who will help?" The experimenter next displayed an image with all three of the new actors depicted side-by-side. The experimenter always introduced the woman in the middle (named "Sophie") first, followed by the other two. The experimenter then explained the transitive, hierarchical structure of authority relationships that the three characters had with one another. This explanation always began with one of the non-central characters, proceeded to Sophie in the middle position (both visually and by rank), and concluded with the other noncentral character. As an example of one sequence of descriptions, the experimenter described the first character as "always in charge... she gets to make all of the rules for [names of the other two characters] and gets to tell both of them what to do", then described Sophie as being "sometimes in charge... she gets to make the rules for [the name of the other non-central character], but still has to listen to what [name of character described as always in charge] says", and finally described the third character as "never in charge... she never gets to make the rules for [names of other two characters] and has to listen to what both of them say." 
RUNNING HEAD: POWER AND PROSOCIAL RESPONSIVENESS

The experimenter then played the video of Sophie dropping and reaching for one of her boxes. After this video, the experimenter advanced the screen so that images of the two noncentral characters were side-by-side, and conducted a method check to confirm that children recalled their authority rankings. Finally, the experimenter asked the child to point to the character that they thought would help Sophie get the box.

Adults completed an identical sequence, with written task instructions.

Design. The first two trials (i.e., “Will she help?”) comprised a within-subject design (Condition: The potential helper was either in charge or not in charge). Across participants, we counterbalanced condition order and the actor pair in each condition. Additionally, we counterbalanced the order in which the experimenter stated the response options ("keep reading" or "stop to help") when asking the child to predict what the potential helper would do. The potential helper always appeared on the right and the needy character on the left.

For the third trial (i.e., "Who will help?"), we counterbalanced the left/right location of the potential helpers, which of these characters was described as always in charge, and whether the experimenter introduced all three characters beginning on the left or right.

Coding. On the first two trials, children responded verbally, and their responses were coded for consistency with saying that the potential helper would "stop [reading] to help". On the third trial, children responded by pointing, and these points were coded for consistency with indicating the character described as "always in charge".

Two independent coders recorded the responses of 52 children (approx. 81\%) from video recordings and their initial agreement was perfect. Responses from the remaining 12 children were taken from audio recordings. The experimenter echoed the children's verbal response on 
RUNNING HEAD: POWER AND PROSOCIAL RESPONSIVENESS

the first two trials (e.g., "You said she would [help/keep reading].") and the child's selection on the third trial (e.g., "You said that [characters' name] would help.").

Statistical Approach. Preliminary analyses found no influence of any of the counterbalancing factors or participant gender. Most importantly, on the first two trials ("Will she help?"), neither the order in which participants were asked about an authority versus a subordinate, nor the order in which the experimenter mentioned the response options, significantly influenced participants' choices.

The main analyses proceeded in two steps, conducted separately for responses to the first two trials and the third trial. First, as in Experiment 1, we created models to assess the effects of the relevant predictors on children's responses. For the first two trials, we created a Generalized Linear Mixed Model containing a random intercept term identifying subjects to account for repeated measures. Condition, Age Group, and their interaction were included as predictors of participants' dichotomous judgments across trials. For the third trial, we created a Generalized Linear Model using a binomial link function. The factor Age Group was included as a predictor of participant's dichotomous judgments. For the first model, each main effect was assessed using a Type-III Wald chi-square test due to the inclusion of the interaction term; a Type-II test was used in the second model. Second, we analyzed performance on each measure at each level of Age Group. For trials 1 and 2, this included both binomial tests and McNemar's test to compare across conditions; for trial 3 , this was a binomial test (chance $=.50$ ).

\section{Results}

Figure 4 presents participants' responses to all three trials.

Trials 1 and 2: "Will she help?" There was not a significant effect of either Condition, $\chi^{2}(1)=1.23, p=.267$, or Age Group, $\chi^{2}(1)=3.03, p=.220$. However, there was a significant 
interaction between these factors, $\chi^{2}(2)=6.37, p=.041$. Younger children showed a nonsignificant tendency to say that the reading woman would help when she was in charge $(22 / 32, p$ $=.0501)$ and had no consistent intuitions about her when she was not in charge $(18 / 32, p=.597)$. Older children showed the opposite pattern: They did not have consistent intuitions about the reading woman when she was in charge $(16 / 32, p=1.00)$ and showed a non-significant tendency to say she would help when she was not in charge $(22 / 32, p=.0501)$. Adults generally indicated that the reading women would help under both descriptions; however, this trend was only significant in the "not in charge" condition (in charge: $22 / 32, p=.0501$; not in charge: $29 / 32, p<$ $.001)$.

Reflecting the significant Condition x Age interaction in the GLM, the influence of Condition varied across ages. Younger children showed a non-significant tendency to say an authority would help a subordinate but not the reverse, whereas older children showed a nonsignificant tendency to say the opposite (McNemar test; younger children: $\chi^{2}(1)=1.14, p=$ .285 ); older children: $\left.\chi^{2}(1)=3.00, p=.083\right)$. Like older children, adults tended to say that a subordinate would help an authority but not the reverse, but at this age the pattern was significant $\left(\chi^{2}(1)=5.44, p=.020\right)$

Trial 3: "Who will help?" There was a significant effect of Age Group $\chi^{2}(1)=13.90, p$ $<.001$. Younger children did not have consistent intuitions about who would help $(16 / 32, p=$ 1.00). However, both older children $(5 / 32, p<.001)$ and adults $(4 / 32, p<.001)$ rarely said that the highest-ranked character would help Sophie; nearly all predicted that the lowest-ranked character would help her.

\section{Discussion}


RUNNING HEAD: POWER AND PROSOCIAL RESPONSIVENESS

Experiment 2 provides further insight into the development of people's intuitions linking power and prosociality. When asked to predict whether one person was likely to help another, there were clear differences between age groups. Neither younger nor older children held consistent intuitions about what a potential helper would do: Younger children showed only a non-significant tendency to view authorities as helpers, older children showed only a nonsignificant tendency to view subordinates as helpers, and neither group's judgments varied according to a potential helper's authority status. However, adults consistently predicted that a subordinate would help, in addition to showing a non-significant tendency to predict an authority would help as well, and they showed much greater consensus regarding the prosocial responsiveness of subordinates than authorities.

When asked explicitly to choose whether an authority or subordinate would help a third person whose rank fell between the ranks of the two potential helpers, a similar pattern emerged. Whereas younger children's designations were at chance, older children and adults agreed strongly that a subordinate would be more likely than an authority to help.

Across multiple measures, Experiment 2 thus indicates that the tendency to view subordinates as more likely than authorities to help increases with age, with 6- to 7-year-olds beginning to make predictions that are similar to adults' predictions.

\section{General Discussion}

How do people expect powerful figures to respond to the needs of others? We investigated 4- to 7-year-old children's and adults' intuitions about links between relative authority, helpful action, and unhelpful inaction. At least one judgment in this domain emerges early and is stable across development: At all ages tested, participants viewed a character who did not help another person as holding authority over her (Experiment 1). Yet the converse 
judgment appeared more gradually: Only older children and adults predicted that an authority figure would be less likely to provide help than a subordinate (Experiment 2).

Overall, these findings establish that young children already draw connections between power and prosociality. Despite the complexity of authorities' actual behaviors across social contexts, children as young as 4 years share adults' intuition that authorities are more likely to be indifferent to others' needs. This is the first demonstration that vertical, hierarchical relationships—just like horizontal, affiliative ones (e.g., Jin \& Baillargeon, 2017)—influence children's expectations about the prosocial responsiveness of others. An additional strength of the present work is that it asks participants to reason in different ways from evidence of relative authority, helpfulness, and unhelpfulness. As discussed below, younger children do not make all of the same inferences as older children and adults, and there are some inferences in this domain that even adults do not make. These patterns provide insight into how children's theories linking power and prosociality develop.

This study focused on preschool-age children's intuitions about the helpfulness of unfamiliar authority figures. However, there are many forms of hierarchy and many ways to support another person (Dunfield, 2014; Terrizzi et al., 2019). To the extent that children distinguish between different power dynamics (e.g., authority, dominance, prestige), social roles (e.g., teachers, parents, bosses), varieties of prosociality (e.g., helping, sharing, comforting), and other forms of interpersonal support (e.g., being empathic or forgiving), their intuitions about power and prosociality may be highly situation-specific. Such detailed intuitions may support expectations that track the complexities of real-world prosocial responses; after all, in a given situation, some powerful people may be more compassionate than others, and certain authority figures such as teachers or parents may feel particularly compelled to help. Alternatively, if 
RUNNING HEAD: POWER AND PROSOCIAL RESPONSIVENESS

children's notions of power and prosociality are each less differentiated, or if they prioritize evidence from particular experiences (Johnson, Dweck, \& Chen, 2007), children's intuitions may not make these fine-grained distinctions. It is also possible that children's intuitions about power and prosociality arise from even more general expectations; for instance, they may believe that high-ranking individuals are prone to ignore any behaviors of their subordinates (e.g., conversational bids). We thus view the present work as a first step in a broader investigation.

Such considerations also raise the possibility that, although participants in Experiment 1 made similar judgments across ages, the theories underlying those judgments may be changing. For instance, children's judgments may have arisen from a very broad expectation about how powerful people respond to others, whereas adults' judgments may have focused more specifically on links between unresponsiveness to another person's instrumental need and one's status as a rule-maker — or perhaps children's first intuitions are limited to this specific concrete situation and only later become more general.

Experiment 1 revealed an unexpected limitation in what inferences these social theories support: Participants did not view helpfulness and unhelpfulness as equally diagnostic of hierarchical power differences. Whereas all age groups identified unhelpful people as authority figures, none made the inverse judgment of identifying helpful people as subordinates; nor did they infer that a person who receives help must be an authority. As noted in the Experiment 1 Discussion, this could have arisen if participants believed that both authorities and subordinates typically help one another, but that authorities are nevertheless more likely to withhold help from subordinates than the reverse. Experiment 2 provided partial support for this model of participants' intuitions. Adults tended to view both subordinates and authorities as likely to help if needed (albeit, predictions for the subordinate were non-significant at $p=.0501$ ), but they also 
RUNNING HEAD: POWER AND PROSOCIAL RESPONSIVENESS

indicated that an authority would be less likely than a subordinate to do so-much as the model would predict. However, older children's judgments only matched some aspects of this pattern, and younger children's judgments matched even fewer. More research is needed to determine whether the tasks used in Experiment 2 adequately captured children's intuitions and whether an alternative account better explains the different probative values of helping and not helping.

A comparison of the developmental timelines obtained in Experiments 1 and 2 provides further insight into children's developing theories of power and prosociality. In Experiment 1, participants as young as 4 years used information about a character's prosocial responsiveness to infer her authority status. In contrast, in Experiment 2, only from 6 years did they use information about a character's authority status to predict her prosocial responsiveness. This asymmetry - that younger children infer authority from unhelpfulness but do not predict unhelpfulness from authority—requires an explanation.

Because children as young as 4 years are able to make both behavior-to-trait and trait-tobehavior inferences (Liu, Gelman, \& Wellman, 2007), it is unlikely that this asymmetry arose from a domain-general inability to predict what a person will (or will not) do from their personal characteristics. However, other research finds that preschool-age children are worse at making behavior predictions than social evaluations from a person's trait-linked appearance (Charlesworth, Hudson, Cogsdill, Spelke, \& Banaji, 2019). As Charlesworth and colleagues propose, trait-based behavior predictions may require a richer, more extensive understanding of what it means to have that trait (e.g., how one is treated by others, and how such treatment might influence one's own motivations). In short, young children may be able to label unhelpful people as authorities because that directional inference is supported by their general knowledge about patterns of prosocial behavior, but they may yet struggle to predict that authorities will be 
unhelpful because they are still learning what it means to be in charge. This perspective draws support from recent research (Cox \& Devine, 2015) emphasizing that Group-Attribute stereotypes may be bidirectional (as was the case for older children and adults in the present work), unidirectional from Group to Attribute, or unidirectional from Attribute to Group (as was the case for younger children). Because the directionality of associations reflects how a stereotype is "learned, reinforced, or used" (Cox \& Devine, 2015), changes in these patterns may reveal what social experiences contribute to children's construction of knowledge in this domain.

The present work also introduces new questions about children's theories of power and prosociality. First, at what point do children reason causally about the influence of power on prosociality? We have documented a conceptual structure that supports inferences in some directions but not others. These asymmetries are consistent with the proposal that concepts of relative authority, helpful action, and unhelpful inaction are bound by semantic knowledge that influences the strengths and meanings of each link (Popov et al., 2019). However, the present study only documents these associations and the inferences they support—it does not reveal why children think those links exist. Do children believe that being an authority actually makes people less helpful? Or that a willingness to be unhelpful makes it easier to attain power? Future research could investigate whether children adjust their helping predictions after they witness a character gain or lose power. It would also be productive to examine children's reasoning about why authorities are sometimes less helpful—do they provide coherent explanations, making sensible reference to psychological states (e.g., reduced attention to others' experiences) or motivations (e.g., less dependence on others' good will)?

Second, do children's theories of power and prosociality invoke normative reasoning? Their theories may simply capture the statistics of helping behaviors - but they may also 
reference norms about how authorities ought to respond. In some contexts, prescriptive norms governing interpersonal behavior apply unevenly across power differentials. For instance, people higher in power feel free to express their emotions genuinely, whereas people lower in power tend to adopt happy expressions, regardless of their subjective state (Hecht \& LaFrance, 1998). In the present study, participants may have reasoned that authorities actually have the privilege to be unhelpful if they so choose, that authorities feel they have such privilege even if others would disagree, or that authorities accept that universal standards of prosocial responsiveness apply to them but flout them anyway. Each of these is an example of a causal account predicated on an understanding that social norms influence how people feel they should behave. Moreover, it is possible that children do not just use norms about power and prosociality to explain others' choices, but that they also adopt those norms in their own judgments about what behaviors are appropriate. Just as earlier research has found that children sometimes view a friend's failure to help as worse than a stranger's (Miller, Bersoff, \& Harwood, 1990), future studies could investigate these issues by asking children to evaluate the acceptability of an authority's unhelpful inaction.

Finally, the present work illuminates recent research on how children infer relative power and their affective preferences for those who appear powerful. Infants infer dominance from victory in zero-sum conflicts, and toddlers prefer agents who win such conflicts because others defer to them (Thomas et al., 2018; Thomsen et al., 2011). Yet we found that children did not view a person who received help as nicer than, or holding authority over, the helper. This suggests that children may distinguish between deference (i.e., prioritizing another's goal over one's own competing goal) and helping (i.e., supporting another's goal in the absence of a competing goal). Moreover, although children may sometimes prefer to affiliate with "high 
RUNNING HEAD: POWER AND PROSOCIAL RESPONSIVENESS

status" individuals (Horwitz, Shutts, \& Olson, 2014), the current findings clearly demonstrate that they can recognize someone as an authority without also liking them. It is an open question what strategic considerations might lead children to affiliate with a high-ranking, unhelpful authority.

\section{Limitations}

This study documents several instances of significant consensus about the prosocial responsiveness of authority figures. However, it does not explain why individual participants may have disagreed with these group trends. Although we asked participants to think about the prosocial responsiveness of unfamiliar authorities in general, it is possible that certain authority types or specific authority figures came to mind. It will be important for future research to consider how children's personal histories with authority figures impact their intuitions about the prosocial responsiveness of both particular authority types and of powerful people in general.

These considerations also highlight the roles that group identity and culture play in shaping one's attitudes toward authority. Communities may disagree for good reason about the prosociality of certain authority types. For example, both the frequency and quality of people's interactions with police are highly variable across racial, economic, and other socio-cultural identities (Brunson \& Weitzer, 2009; Carr, Napolitano, \& Keating, 2007), and these experiences shape children's and adolescent's beliefs about the legitimacy of institutional authority (Fagan \& Tyler, 2005). This raises two major limitations of the present work. First, this study was not designed to examine associations between demographic variation (e.g., socio-economic status, race, ethnicity) within our sample and the judgments that participants made. Second, our majority-White sample is not economically or culturally representative of all communities within the United States or around the world. 
RUNNING HEAD: POWER AND PROSOCIAL RESPONSIVENESS

It is also possible that the personal characteristics of our actors influenced participants' views of them as authority figures. For instance, preschool-age children use gender to interpret power dynamics (Charafeddine et al., 2020). Because the actors in the current studies were all female, we do not know whether our results would generalize to male authority figures; moreover, it would be worthwhile for future research to examine how viewing low status characters as likely helpers may contribute to, or reflect, emerging gender stereotypes. Additionally, although the actors introduced in Experiment 1 were White, Experiment 2 featured a trio of South Asian actors; we do not know if this contributed to differences between experiments. Future research should investigate how an authority's social identity influences participants' judgments about their prosocial responsiveness. 


\section{References}

Ball, S. (1998). The Economic Value of Status. Journal of Socio-Economics, 24(4), 495-514. http://doi.org/10.1016/s1053-5357(99)80104-8

Barclay, P. (2013). Strategies for cooperation in biological markets, especially for humans. Evolution and Human Behavior, 34(3), 164-175.

http://doi.org/10.1016/j.evolhumbehav.2013.02.002

Brey, E., \& Shutts, K. (2015). Children Use Nonverbal Cues to Make Inferences About Social Power. Child Development, 86(1), 276-286. http://doi.org/10.1111/cdev.12334

Brunson, R. K., \& Weitzer, R. (2009). Police Relations with Black and White Youths in Different Urban Neighborhoods. Urban Affairs Review, 44(6), 858-885. http://doi.org/10.1177/1078087408326973

Carr, P. J., Napolitano, L., \& Keating, J. (2007). We never call the cops and here is why: A qualitative examination of legal cynicism in three Philadelphia neighborhoods. Criminology, 45(2), 445-480.

Charafeddine, R., Mercier, H., Clément, F., Kaufmann, L., Berchtold, A., Reboul, A., \& Van der Henst, J.B. (2014). How Preschoolers Use Cues of Dominance to Make Sense of Their Social Environment. Journal of Cognition and Development, 16(4), 587-607. http://doi.org/10.1080/15248372.2014.926269

Charafeddine, R., Zambrana, I. M., Triniol, B., Mercier, H., Clément, F., Kaufmann, L., ... \& Van der Henst, J. B. (2020). How Preschoolers Associate Power with Gender in MaleFemale Interactions: A Cross-Cultural Investigation. Sex Roles, 1-21. 
Charlesworth, T. E. S., Hudson, S.-K. T. J., Cogsdill, E. J., Spelke, E. S., \& Banaji, M. R. (2019). Children use targets' facial appearance to guide and predict social behavior. Developmental Psychology, 1-15. http://doi.org/10.1037/dev0000734

Cheng, J. T., Tracy, J. L., \& Henrich, J. (2010). Pride, personality, and the evolutionary foundations of human social status. Evolution and Human Behavior, 31(5), 334-347. http://doi.org/10.1016/j.evolhumbehav.2010.02.004

Côté, S., Kraus, M. W., Cheng, B. H., Oveis, C., van der Löwe, I., Lian, H., \& Keltner, D. (2011). Social power facilitates the effect of prosocial orientation on empathic accuracy. Journal of Personality and Social Psychology, 101(2), 217-232. http://doi.org/10.1037/a0023171

DeCelles, K. A., DeRue, D. S., Margolis, J. D., \& Ceranic, T. L. (2012). Does power corrupt or enable? When and why power facilitates self-interested behavior. Journal of Applied Psychology, 97(3), 681-689. http://doi.org/10.1037/a0026811

Dunfield, K. A. (2014). A construct divided: prosocial behavior as helping, sharing, and comforting subtypes. Frontiers in Psychology, 5(1132), 958. http://doi.org/10.3389/fpsyg.2014.00958

Enright, E. A., Gweon, H., \& Sommerville, J. A. (2017). "To the victor go the spoils": Infants expect resources to align with dominance structures. Cognition, 164, 8-21. http://doi.org/10.1016/j.cognition.2017.03.008

Fagan, J., \& Tyler, T. R. (2005). Legal Socialization of Children and Adolescents. Social Justice Research, 18(3), 217-241. http://doi.org/10.1007/s11211-005-6823-3 
RUNNING HEAD: POWER AND PROSOCIAL RESPONSIVENESS

Fiddick, L., Cummins, D. D., Janicki, M., Lee, S., \& Erlich, N. (2013). A Cross-Cultural Study of Noblesse Oblige in Economic Decision-Making. Human Nature, 24(3), 318-335. http://doi.org/10.1007/s12110-013-9169-9

Galinsky, A. D., Magee, J. C., Inesi, M. E., \& Gruenfeld, D. H. (2006). Power and Perspectives Not Taken. Psychological Science, 17(12), 1068-1074. http://doi.org/10.1111/j.14679280.2006.01824.x

Grueneisen, S., \& Tomasello, M. (2017). Children coordinate in a recurrent social dilemma by taking turns and along dominance asymmetries. Developmental Psychology, 53(2), 265-273. http://doi.org/10.1037/dev0000236

Guinote, A. (2017). How Power Affects People: Activating, Wanting, and Goal Seeking. Annual Review of Psychology, 68(1), 353-381. http://doi.org/10.1146/annurev-psych-010416044153

Guinote, A., Cotzia, I., Sandhu, S., \& Siwa, P. (2015). Social status modulates prosocial behavior and egalitarianism in preschool children and adults. Proceedings of the National Academy of Sciences, 112(3), 731-736. http://doi.org/10.1073/pnas.1414550112

Gülgöz, S., \& Gelman, S. A. (2016). Who's the Boss? Concepts of Social Power Across Development. Child Development, 1-23. http://doi.org/10.1111/cdev.12643

Hawley, P. H. (2002). Social dominance and prosocial and coercive strategies of resource control in preschoolers. International Journal of Behavioral Development, 26(2), 167-176. http://doi.org/10.1080/01650250042000726

Henrich, J., \& Gil-White, F. J. (2001). The evolution of prestige: Freely conferred deference as a mechanism for enhancing the benefits of cultural transmission. Evolution and Human Behavior, 22(3), 165-196. http://doi.org/10.1016/s1090-5138(00)00071-4 
Horn, L., Hungerländer, N. A., Windhager, S., Bugnyar, T., \& Massen, J. J. M. (2018). Social status and prenatal testosterone exposure assessed via second-to-fourth digit ratio affect 6-9year-old children's prosocial choices. Scientific Reports, 8(1), 9198. http://doi.org/10.1038/s41598-018-27468-0

Horwitz, S. R., Shutts, K., \& Olson, K. R. (2014). Social class differences produce social group preferences. Developmental Science, 17(6), 991-1002. http://doi.org/10.1111/desc.12181

Jin, K.-S., \& Baillargeon, R. (2017). Infants possess an abstract expectation of ingroup support. Proceedings of the National Academy of Sciences, 114(31), 8199-8204. http://doi.org/10.1073/pnas.1706286114

Johnson, S. C., Dweck, C. S., \& Chen, F. S. (2007). Evidence for infants' internal working models of attachment. Psychological Science, 18(6), 501-502. http://doi.org/10.1111/j.14679280.2007.01929.x

Kafashan, S., Sparks, A., Griskevicius, V., \& Barclay, P. (2014). Prosocial Behavior and Social Status. In J. T. Cheng, J. L. Tracy, \& C. Anderson (Eds.), The Psychology of Social Status (pp. 139-158). New York, NY: Springer New York. http://doi.org/10.1007/978-1-49390867-7_7

Kraus, M. W., Côté, S., \& Keltner, D. (2010). Social Class, Contextualism, and Empathic Accuracy. Psychological Science, 21(11), 1716-1723. http://doi.org/10.1177/0956797610387613

Liberman, Z., \& Shaw, A. (2017). Children use partial resource sharing as a cue to friendship. Journal of Experimental Child Psychology, 159, 1-14. http://doi.org/10.1016/j.jecp.2017.02.002 
Liu, D., Gelman, S. A., \& Wellman, H. M. (n.d.). Components of young children's trait understanding: Behavior-to-trait inferences and trait-to-behavior predictions. Developmental Psychology, 78, 1543-1558.

Margoni, F., Baillargeon, R., \& Surian, L. (2018). Infants distinguish between leaders and bullies. Proceedings of the National Academy of Sciences of the United States of America, 115(38), E8835-E8843. http://doi.org/10.1073/pnas.1801677115

Mascaro, O., \& Csibra, G. (2012). Representation of stable social dominance relations by human infants (Vol. 109, pp. 6862-6867). Presented at the Proceedings of the National Academy of Sciences, National Acad Sciences. http://doi.org/10.1073/pnas.1113194109

Miller, J. G., Bersoff, D. M., \& Harwood, R. L. (1990). Perceptions of social responsibilities in India and in the United States: Moral imperatives or personal decisions? Journal of Personality and Social Psychology, 58(1), 33-47. http://doi.org/10.1037/0022-3514.58.1.33

Pellegrini, A. D., Van Ryzin, M. J., Roseth, C., Bohn-Gettler, C., Dupuis, D., Hickey, M., \& Peshkam, A. (2011). Behavioral and social cognitive processes in preschool children's social dominance. Aggressive Behavior, 37(3), 248-257. http://doi.org/10.1002/ab.20385

Pun, A., Birch, S. A. J., \& Baron, A. S. (2016). Infants use relative numerical group size to infer social dominance. Proceedings of the National Academy of Sciences, 113(9), 2376-2381. http://doi.org/10.1073/pnas.1514879113

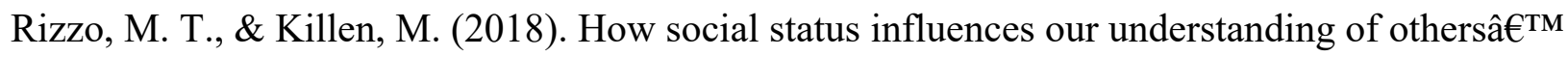
mental states. Journal of Experimental Child Psychology, 169, 30-41. http://doi.org/10.1016/j.jecp.2017.12.008

Scholl, A., de Wit, F., Ellemers, N., Fetterman, A. K., Sassenberg, K., \& Scheepers, D. (2018). The Burden of Power: Construing Power as Responsibility (Rather Than as Opportunity) 
RUNNING HEAD: POWER AND PROSOCIAL RESPONSIVENESS

Alters Threat-Challenge Responses. Personality and Social Psychology Bulletin, 44(7), 1024-1038. http://doi.org/10.1177/0146167218757452

Spokes, A. C., \& Spelke, E. S. (2016). Children's Expectations and Understanding of Kinship as a Social Category. Frontiers in Psychology, 7(e23223), 773-13.

http://doi.org/10.3389/fpsyg.2016.00440

Terrizzi, B. F., Brey, E., Shutts, K., \& Beier, J. S. (2019). Children's developing judgments about the physical manifestations of power. Developmental Psychology, 55(4), 793-808.

http://doi.org/10.1037/dev0000657

Thomas, A. J., Thomsen, L., Lukowski, A. F., Abramyan, M., \& Sarnecka, B. W. (2018).

Toddlers prefer those who win but not when they win by force. Nature Publishing Group, 2(9), 662-669. http://doi.org/10.1038/s41562-018-0415-3

Thomsen, L., Frankenhuis, W. E., Ingold-Smith, M., \& Carey, S. (2011). Big and Mighty:

Preverbal Infants Mentally Represent Social Dominance. Science, 331(6016), 477-480. http://doi.org/10.1126/science.1199198

van de Ven, N., Zeelenberg, M., \& Pieters, R. (2010). Warding Off the Evil Eye: When the Fear of Being Envied Increases Prosocial Behavior. Psychological Science, 21(11), 1671-1677. http://doi.org/10.1177/0956797610385352

Van Kleef, G. A., Homan, A. C., Finkenauer, C., Blaker, N. M., \& Heerdink, M. W. (2012). Prosocial norm violations fuel power affordance. Journal of Experimental Social Psychology, 48(4), 937-942. http://doi.org/10.1016/j.jesp.2012.02.022 


\section{Helpful Condition}
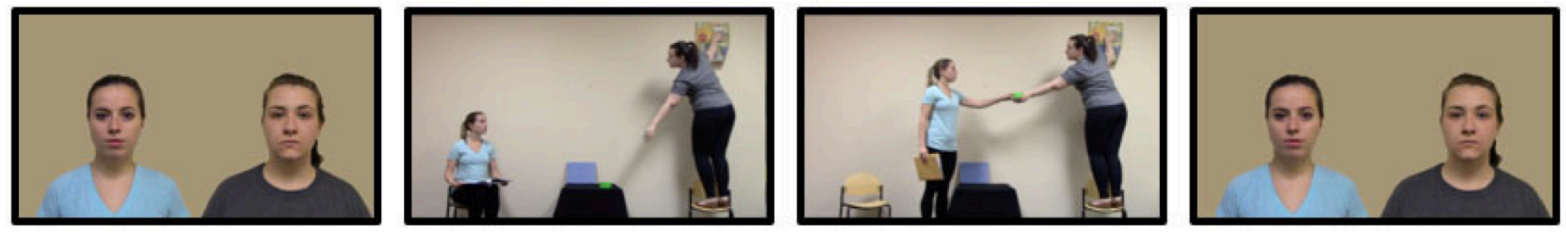

\section{Unhelpful Condition}

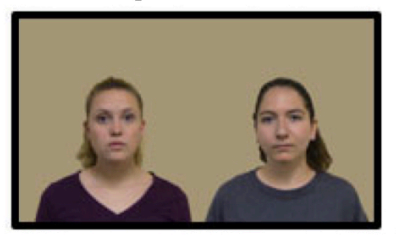

Character Introductions

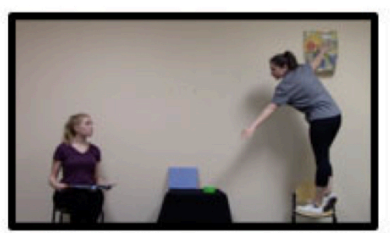

Display of Need

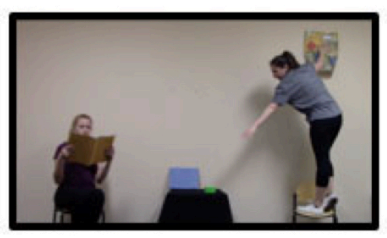

Character Response

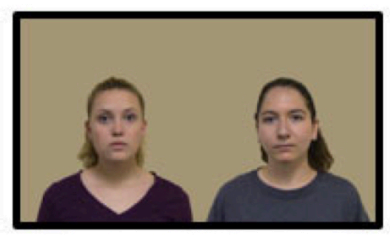

Test Questions

14-second video sequence

Figure 1. Schematic depiction of the test sequence for each condition in Experiment 1. The critical portions of the "Display of Need" and "Character Response" sequence lasted 14 seconds; total video durations (with characters' arrivals and getting into position) were approximately 30 seconds. 


\section{Proportion Selecting the Helpful/Unhelpful Character Over the Character in Need}

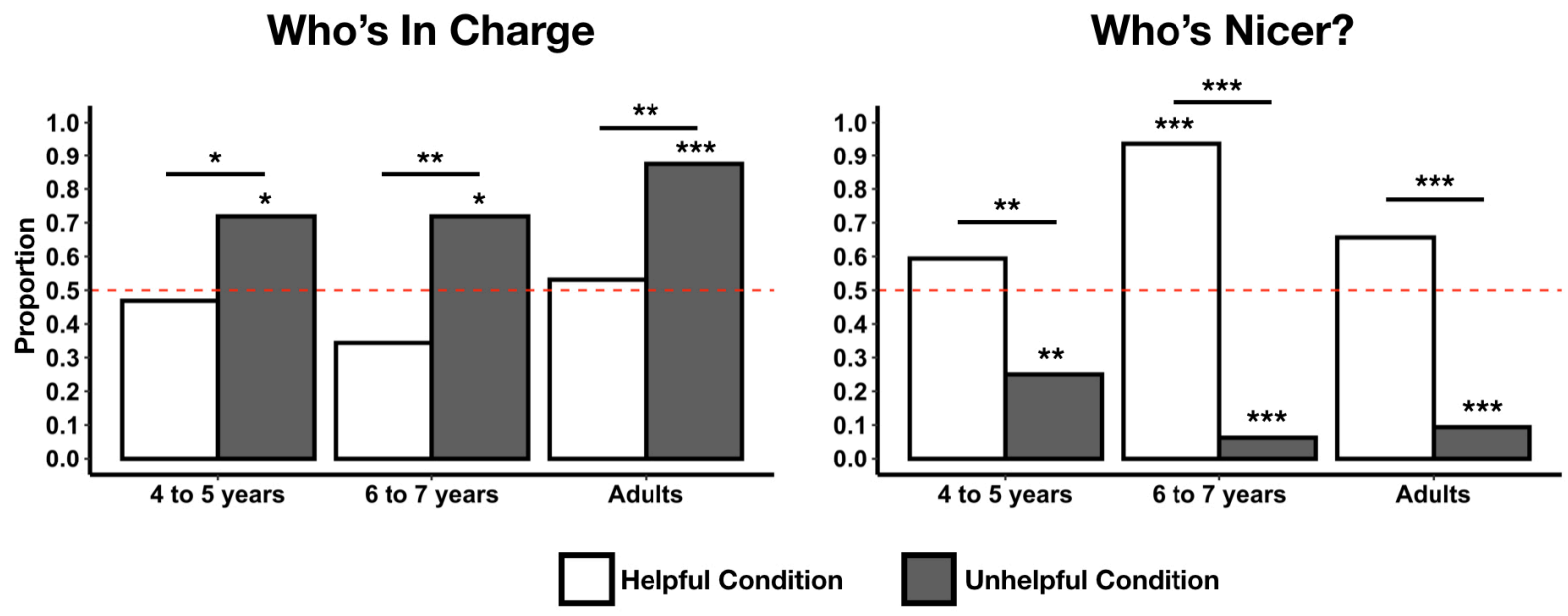

Figure 2. Results for Experiment 1. The proportion of participants selecting the focal character for each question type and condition. The focal character was the helpful person in the Helpful Condition and the unhelpful person in the Unhelpful condition. $* p<.05, * * p<.01, * * * p<$ .001 


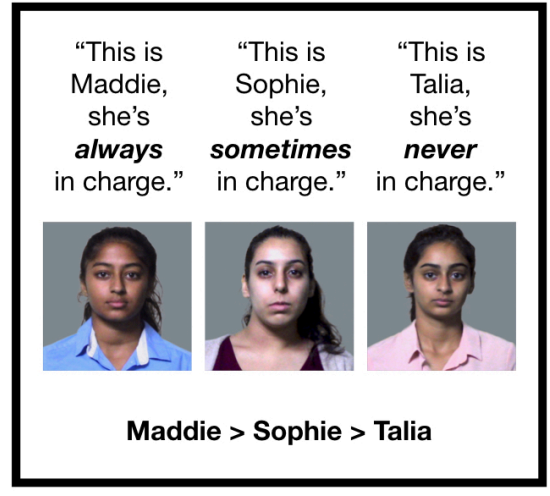

Character Introductions

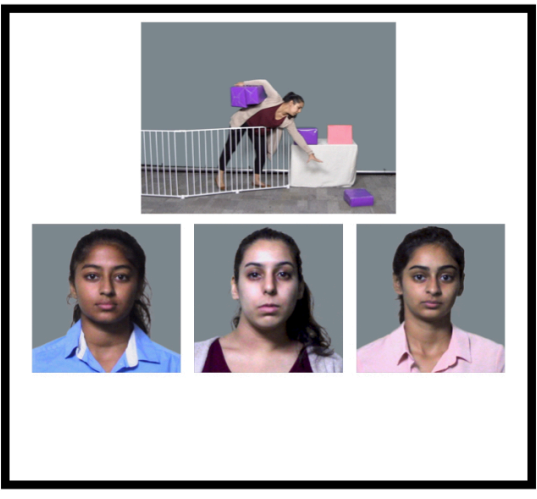

Display of Need

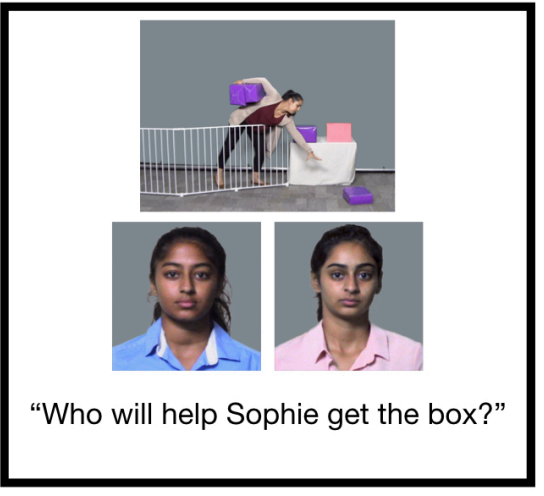

Test Question

14-second video sequence

Figure 3. Schematic depiction of the test sequence for Trial 3 of Experiment 2 ("Who Will Help?"). Each character's authority status was defined both individually (e.g., “...she's always in charge") and interpersonally (e.g., "...she makes the rules for both Sophie and Talia...”). The critical reaching portion of the "Display of Need" event lasted 10 seconds; total video duration (with the protagonist's arrival and dropping of the box over the fence) was approximately 14 seconds. The text written within each frame was not displayed on the screen, but is included here for illustrative purposes. 


\section{Will She Help?}

Proportion Saying "Yes"

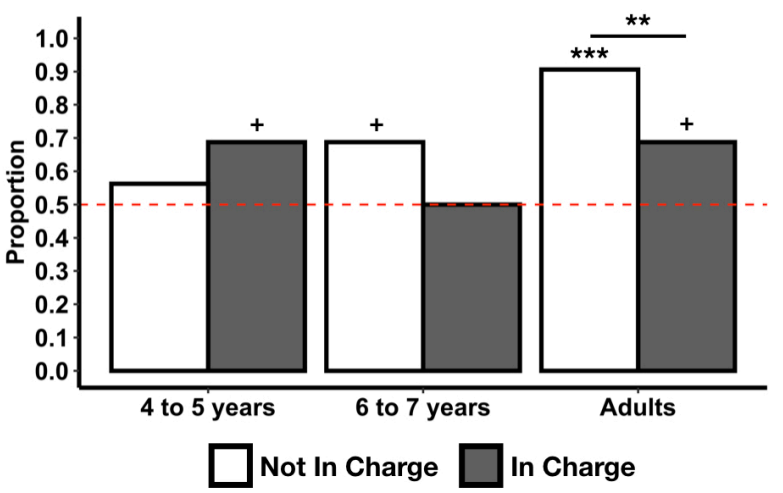

Who Will Help?

Proportion selecting

high vs. low authority

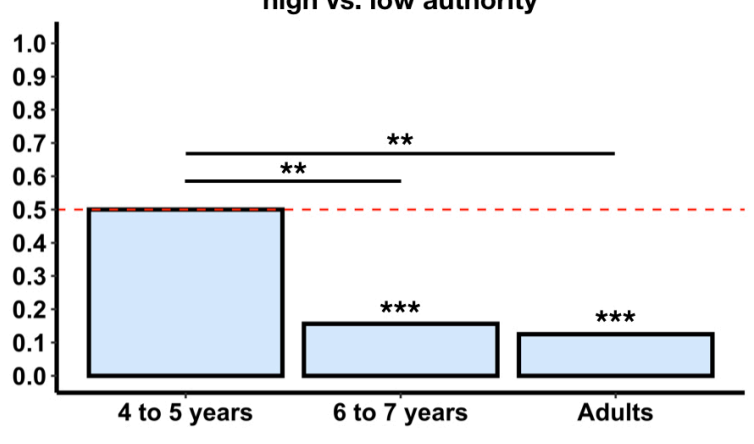

Figure 4. Results for Experiment 2. Trials 1 and 2, "Will She Help?": The proportion of participants saying the reading woman would help the character in need, when the reader was described as being "not in charge" and "in charge". Trial 3, "Who Will Help?": The proportion of participants indicating that the "always in charge" character was more likely to help than the "never in charge" character. ${ }^{+} \mathrm{p}=.05, * * p<.01, * * * p<.001$ 
Supplementary Materials for:

\title{
Young children and adults associate social power with indifference to others' needs
}

\author{
Brandon F. Terrizzi ${ }^{1}$ \\ Amanda M. Woodward ${ }^{2}$ \\ Jonathan S. Beier ${ }^{2}$ \\ ${ }^{1}$ Cincinnati Children's Hospital Medical Center, Cincinnati, Ohio, USA \\ ${ }^{2}$ University of Maryland, College Park, Maryland, USA
}

The original materials and data accompanying this study are available at the Open Science Framework: https://osf.io/36yz2/?view_only=5ac38a83c8814841a92daf9bc9a4bb82.

\author{
Corresponding Author Information: \\ Brandon F. Terrizzi, PhD \\ Division of General \& Community Pediatrics \\ Cincinnati Children's Hospital Medical Center \\ 3333 Burnet Avenue \\ Cincinnati, OH 45229 \\ Email: Brandon.Terrizzi@cchmc.org \\ Phone: +1 5138038817
}


RUNNING HEAD: POWER AND PROSOCIAL RESPONSIVENESS

\section{Supplemental Materials}

\section{Experiment 1}

\section{Additional Participant Information}

See Table $S 1$ for parent-reported race and ethnicity of child participants. Participant sex was indicated by parents for children and self-identified by adults. There were 17 girls and 15 boys in our sample of younger children, 19 girls and 13 boys in our sample of older children, and 24 females and 8 males in our adult sample.

\section{Additional Analyses}

Who's in charge? Prompted by the Condition x Age Group interaction for the "Who's nicer" question (reported in the main article), for completeness of reporting, we provide similar analyses for the "Who's in charge" question, even though the Condition x Age Group interaction for this question was not significant. Examining each age group with a McNemar test, participants in every age group were more likely to say that the unhelpful character was in charge (relative to the character who required help) than to say that the helpful character was in charge (relative to the character who required and received help): younger children: $\chi^{2}(1)=4.57, p=$ .032 ; older children: $\chi^{2}(1)=9.00, p=.003$; adults: $\chi^{2}(1)=8.07, p=.005$.

Associations between question types. Table S2 presents phi coefficients of association between participants' responses to each question type, separately for each condition. Both younger and older children who selected one character as in charge tended to say that the other character was nicer. This was true when they were comparing the helpful and needy characters and when comparing the unhelpful and needy characters. We observed similar patterns among adults, but these associations were not significant. 
Table S1. Child Race and Ethnicity

\begin{tabular}{lcc}
\hline Race, Ethnicity & $\mathbf{n}$ & $\mathbf{\%}$ \\
\hline White, Non-Hispanic & 35 & 54.69 \\
Black, Non-Hispanic & 17 & 26.56 \\
White, Hispanic & 5 & 7.81 \\
Black, Hispanic & 4 & 6.25 \\
Asian, Non-Hispanic & 2 & 3.13 \\
Native Hawaiian or Pacific Islander, Non-Hispanic & 1 & 1.56 \\
\hline Total & $\mathbf{6 4}$ & $\mathbf{1 0 0 . 0 0}$ \\
\hline
\end{tabular}

Table S1. Distribution of children's parent-reported race and ethnicity in Experiment 1.

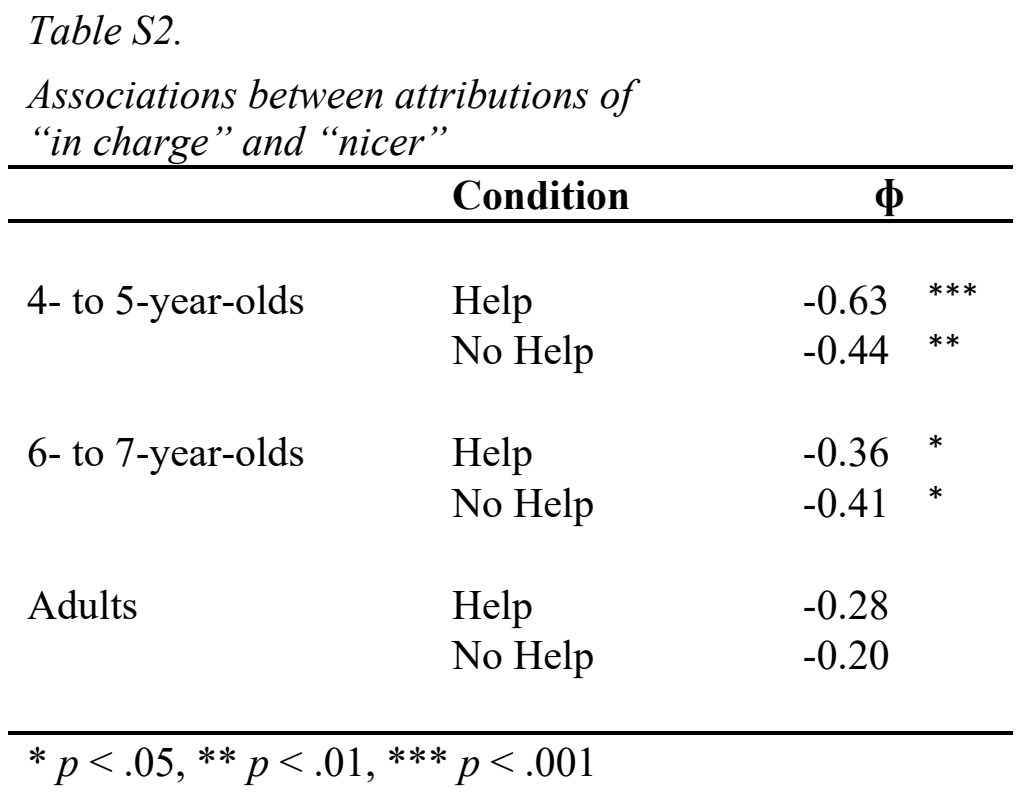

Table S2. Phi coefficients of association between participants' responses to each question in both conditions in Experiment 1. 